\title{
Transparency goes a long way: information transparency and its effect on job satisfaction and turnover intentions of the professoriate
}

\author{
Yvette E. Hofmann ${ }^{1,2}$. Maria Strobel ${ }^{1,3,4}$
}

Published online: 24 April 2020

(c) The Author(s) 2020

\begin{abstract}
Research and higher education institutions are becoming increasingly transparent with the adoption of the governance mechanisms of New Public Management and digital technologies. As transparency research has documented both positive and negative effects of transparency within organizations, it is not clear how transparency might affect faculty members and their job attitudes. To address this question, we develop and test hypotheses regarding the effect of perceived transparency on professors' job satisfaction and intent to leave their university. Our results, based on the answers of over 1600 professors, support our hypothesized positive relationship between transparency and job satisfaction, a negative relationship between transparency and intent to leave, and an indirect effect of transparency on intent to leave via job satisfaction. Exploratory moderation analyses indicated that the effects of transparency are present across two different types of universities (research universities and universities of applied sciences). We discuss results regarding their implications for the management of higher education and research institutions as well as for the retention of faculty members.
\end{abstract}

Keywords Transparency $\cdot$ New public management $\cdot$ Higher education $\cdot$ Job satisfaction · Turnover intention

JEL Classification I23 (Higher education, Research institutions) · J63 (Turnover, Vacancies, Layoffs) · M12 (Personnel management, Executives; Executive compensation)

Yvette E. Hofmann and Maria Strobel shared first authorship

Extended author information available on the last page of the article 


\section{Introduction}

With the adoption of New Public Management, governance and performance management of higher education institutions (HEI) increasingly rely on data to monitor administrative structures and processes, as well as performance, in research and teaching (Welpe et al. 2014; Schimank and Lange 2009; Jansen 2007). Digital technologies make it possible to track organizational structures, processes and performance and make them visible in real-time and are increasingly used for this purpose-not only in the "digital star" companies but also in other, more traditional organizations (Tumasjan and Welpe 2017). The increasing availability and visibility of performance data to an organization's internal and external stakeholders is not only a widespread phenomenon in today's organizations but has also become the subject of investigation in management research. A recent review article on transparency in management (Bernstein 2017) begins with the observation that "[w]e are increasingly observed and observing at work" (p. 217), and calls for further investigation of the effects of transparency on organizations and their members. In the higher education context, the systematic tracking and communication of process and performance data are frequently discussed critically, bearing the risk of increasing administrative burden and restricting academic freedom (Tanczer et al. 2016; McCluskey and Winter 2014; Chen 2006). This raises the question of how transparency within HEIs influences professors' satisfaction with their work situation and their commitment to their university.

Existing management research on transparency has mainly focused on profitoriented organizations and enterprises (cf. Bernstein 2017). However, transparency is also a frequently discussed subject with regard to research and HEIs, which are currently facing similar developments regarding the transparency of their organizational structures, processes, and outcomes (e.g., Ramírez et al. 2015; Lynch 2014; Sanchez and Elena 2005). For example, data on the organizational structure of universities, such as the number and composition of students and personnel, are increasingly available in detail to both organizational members and the public (e.g., Destatis 2020). Moreover, there is a debate on the increased monitoring of and focus on performance outcomes in academia with respect to publications and their research impact (Wilsdon et al. 2015; Küpper 2009a, b). Furthermore, education technology start-ups are developing (and HEIs are increasingly using) digital tools, such as performance dashboards, which can be used to monitor entrepreneurial progress and make organizational and/or unit performance visible to organizational members (cf. Wendler et al. 2017). Despite these developments, empirical research on the effects of transparency on organizational members in research and HEIs is still lacking. Concretely, to our knowledge, there are currently no empirical studies focusing on the impact of transparency on professors in universities.

Existing studies on transparency within organizations suggest that transparency may be a double-edged sword: while organizational members may benefit from access to information about strategic and other organizational units - as indicated, for example, by research on informational justice (Colquitt et al. 2001) and knowledge sharing (Cummings 2004) - there is also research pointing to potential negative effects of the availability of information (e.g., Beshears et al. 2015; Bernstein 2012). For example, Bernstein (2012) pointed out an imminent "transparency paradox": On the one hand, 
transparency in organizations has the potential to increase satisfaction by providing feedback and increasing the perceived "informedness" of organizational members. On the other hand, it can also have adverse effects, as organizational members may feel uncomfortable to both provide and receive (too much) information about their organizational surroundings, hampering their feeling of self-determination and potentially increasing competitive pressure (Tapscott and Ticoll 2012; Küpper 2000, 2003). These effects have been shown for profit-oriented organizations, but there is little research so far as to what extent the dependencies found apply to faculty members and university professors. Following Musselin (2004), universities are specific organizations whose governance, organizational, and employment structures differ from those of most other organizations or companies (see also Sandberger 2019; Ren and Li 2013; Bleiklie and Kogan 2007; Thorens 2006; Russell 1993). Usually, a full professor's position is characterized by maximum academic freedom and power alongside minimum accountability to the head of the faculty or the university's administration. Furthermore, professors are relatively self-regulated with a low degree of interference from central authorities and a high degree of autonomy guaranteed by law (e.g., Sandberger 2019; Ren and Li 2013; Thorens 2006; Russell 1993). Moreover, in contrast to company managers, they usually hold tenured positions as civil servants. In these regards, their working situation is substantially different from that of managers. Thus, findings from the management literature about employees' reactions to information transparency are not necessarily transferable or applicable to the professors.

Therefore, the present study, based on the answers of 1606 professors, focuses on the influence of transparency on faculty members. Specifically, we investigate the consequences of perceived transparency in universities on professors' satisfaction with their working conditions and their intention to leave their university. Our research contributes to the literature in the following ways.

First, we advance theory and empirical research on the effects of transparency in HEIs, which is an essential yet underinvestigated issue given the increasing prevalence of management instruments, such as administrative data, processes, and procedures, in such organizations, which enable information disclosure and often result in a higher degree of transparency. We thereby contribute to the literature on New Public Management and governance in research and HEIs (e.g., Küpper 2003, 2009a, b; Paradeise et al. 2009. See also Welpe et al. 2014). This contribution is particularly relevant with respect to the ongoing digital transformation of HEIs (Backes-Gellner et al. 2019; Strobel and Welpe 2017; McCluskey and Winter 2012), which brings an increasing degree of transparency to these organizations, which needs to be understood and managed (cf. Stohl et al. 2016; Küpper 2007). Specifically, we develop and empirically test a model that explains how transparency affects intentions to leave by affecting job satisfaction.

Second, we contribute to the literature on job attitudes and turnover intentions of research and teaching faculty (e.g., O’Meara et al. 2016; Lawrence et al. 2014; Smart 1990) by investigating perceived transparency as a predictor of intent to leave and satisfaction with work conditions. By theoretically deriving and empirically testing the effects of perceived transparency on these two outcomes in an integrated model, we contribute to investigating subjective, transparency-induced effects that manifest themselves in objectively measurable outcomes. Specifically, we add to the under- 
standing of the intermediate effects of transparency on the capability of universities to bind high potentials, fight a potential loss of human capital (i.e., brain drain; e.g., Mayr and Peri 2009; Remhof 2008; Tritah 2008), and maintain competitiveness with other HEIs.

\section{Theory}

To manage HEIs successfully, the collection and handling of information about an organization's structures, processes, and performance are vital (e.g., Randhahn 2017; Mullins 1993; Morton 1991; March and Simon 1958). The same applies to requirements about what information has to be disclosed by universities to consumers, such as students. (e.g., NPEC 2009). The rapid developments in information technology over the past decade supported these activities and increased the degree of transparency within organizations (e.g., Sanchez and Elena 2005; Henderson and Venkatraman 1993). It can be expected that, aside from sheer information overload, information disclosure affects employees' assessment of their working conditions and job satisfaction (e.g., Krayer and Westbrook 1986). Therefore, we concentrate on how university professors experience the disclosure of information (information transparency) and how their experiences with a more or less transparent working environment influence their satisfaction with working conditions and turnover intentions. Starting from an individual point of view, we assume that the main influence factors of information-based behavior are one's perception and assessment of an organization's degree of information transparency. By integrating the findings of generic concepts of information management and job satisfaction theory into a behavioral science theory fundament, we develop a model that explains existing interdependencies between the main variables. In particular, we offer propositions about the relationship between the perceived degree of transparency, transparency-induced satisfaction with working conditions, and turnover intentions of the professoriate at universities.

Since job satisfaction and the management of information represent two of the major research fields in organizational behavior, there have been multiple types of research regarding the crucial dimensions of managing people to enhance their job satisfaction (for a recent review, see Judge et al. 2017). Furthermore, one can also find numerous theoretical accounts and empirical studies on the management of information, concentrating on relevant aspects of information supply, management information systems, and the implementation of information technology and its capability to disclose information (e.g., Cullen et al. 2003; Wigand et al. 1997; O'Reilly et al. 1987; Daft and Lengel 1986; O'Reilly 1983). We assume that information disclosure about a university's structure, processes, and performance results in a specific perception of the degree of transparency by professors. As Eisenberg et al. (1984) have shown, insufficient information causes uncertainty and disengagement among employees while feeling well-informed correlates with feeling appreciated and leads to higher job satisfaction (e.g., Buell et al. 2016; Bozeman and Gaughan 2011; Rosenfeld et al. 2004; Krayer and Westbrook 1986). Based on these findings, we propose that a high organizational transparency results in a positive perception of the degree of transparency by its members and influences their satisfaction. Thus, we suppose that there is a positive 
relationship between a professor's transparency perception and his or her satisfaction with his or her current working conditions.

\section{Hypothesis 1: Perceived transparency will be positively related to professors' satisfaction with their current working conditions.}

This supposition is of particular interest since information transparency carries a challenging ambiguity regarding its consequences. On the one hand, information disclosure seems to have positive consequences and motivational potential (e.g., Lee et al. 2015; Zimmer et al. 2010), so professors might try to give their best when their performance is made transparent to colleagues, subordinates, students, and other stakeholders in a university environment. On the other hand, when employees see their need for information not met or feel dissatisfied by the organization's information policy, this can not only result in counterproductive behavior, work slowdown, or work withdrawal but often increases the employees' turnover intentions (e.g., O'Meara et al. 2016; Miner et al. 2005; Kiefer 2005; Martocchio and Jimeno 2003; Tett and Meyer 1993; Smart 1990). Therefore, we propose that a higher degree of transparency affects not only professors' satisfaction with their working conditions but also their intent to leave.

\section{Hypothesis 2: Perceived transparency will be negatively related to professors' intent to leave their current university.}

In the following section, we develop a model of the motivational process through which transparency exerts its effect on job satisfaction. ${ }^{1}$ Our theorizing is based on Martin's (1979) contextual model of turnover intentions, which contends that structural features of the organization affect intentions to leave by influencing job satisfaction. In line with this model, we propose that the transparency of HEIs affects professors' intent to leave by influencing their job satisfaction. First, as argued in the previous section, we propose that transparency has a positive effect on job satisfaction. Second, previous research has repeatedly and robustly shown that job satisfaction is a strong negative predictor of intent to leave. For example, a meta-analysis by Tett and Meyer (1993) found a weighted mean correlation of -0.58 between job satisfaction and intentions to leave across the 88 samples included in their analysis. In the higher education context, Smart (1990) has also shown significant negative, but weaker relationships between professors' organizational satisfaction and their intent to leave. Thus, we propose that transparency affects turnover intentions by influencing levels of job satisfaction. In building our model, we also considered the possibility of an alternative causal pathway, such that intentions to leave may also influence satisfaction and transparency perceptions, through a mechanism of post hoc rationalization of an already formed intention. However, we follow Martin's (1979) argumentation that successive changes in context variables will lead to successive changes in intent to leave, and argue that this is the main causal direction driving the relationship between transparency and intentions to leave in our model. This direction is also in line with Mobley et al.'s (1979) classical model of turnover, in which organizational variables affect job satisfaction, which in turn predicts thoughts of quitting (and not vice versa). This model has been

\footnotetext{
1 We thank an anonymous reviewer for suggesting the integration of a mediation model into our manuscript.
} 


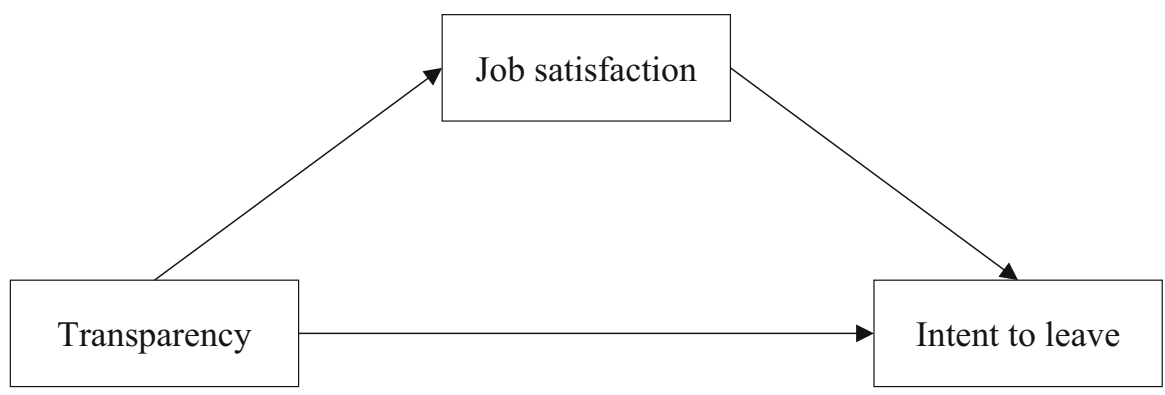

Fig. 1 Effect of perceived transparency on intent to leave mediated by job satisfaction

supported by meta-analytical (Hom et al. 1992) and longitudinal (for review, see Hom et al. 2017) evidence. Thus, in summary, we propose an indirect effect of transparency on intent to leave, such that higher transparency leads to higher job satisfaction, which, in turn, lowers intentions to leave the organization (see Fig. 1).

Hypothesis 3: There will be an indirect effect of perceived transparency on professors' intent to leave their current university through job satisfaction.

\section{Methods}

\subsection{Sample and procedure}

Our study is based on data from a survey of professors in a large German federal state (Bavaria) whose contact information could be retrieved via an internet search. The online survey was aimed at investigating the professors' satisfaction with the working conditions at their universities. Overall, we obtained responses from 2199 participants, of which we excluded those with missing values on any of our study and control variables, yielding a final sample of $N=1606$ participants for analysis. Regarding the composition of our sample compared to the actual academic population, we can provide good representativeness (the reference point is the year 2014; cf. StatB 2014). For instance, of all professors, around $18 \%$ have been female professors, while in our sample we have a headcount of $17.2 \%$ female professors. Furthermore, for most of the subjects, our sample consists of quite a similar percentage compared to the Bavarian academic population. For example, 25.2\% of the professors are from the field of economics, law, and social sciences compared to $23.9 \% ; 24.1 \%$ are from the field of engineering sciences compared to $23.9 \%$; and almost $9 \%$ of professors are from the field of human medicines and health sciences compared to $10 \%$. All professors work at public universities, with $56.8 \%$ of our sample working at research universities and $43.2 \%$ working at public universities of applied sciences (compared to $52.8 \%$ and $38.9 \%$ in the Bavarian academic population). Our sample encompasses professors with ranks equivalent to associate professor or above, according to the German system $(56.1 \% \mathrm{~W} 2,23.7 \% \mathrm{~W} 3,10.6 \% \mathrm{C} 3,9.7 \% \mathrm{C} 4), 96.9 \%$ of which held full-time positions. 


\subsection{Measures}

\subsubsection{Perceived transparency}

Perceived transparency was assessed with a new measure designed for the present study, based on ten expert interviews conducted as part of a preliminary study. The items were generated at the Bavarian State Institute for Higher Education Research and Planning and subsequently reviewed by twelve professors from five different disciplines (business administration, economics, engineering, information technologies, and medicine) for content validity and understandability. The measure encompassed a graphical indicator on which participants were asked to indicate the degree of transparency within their department. The instruction was: "How do you rate the degree of transparency of your department regarding comprehensibility and clarity of departmental structures and processes?-Generally speaking, I perceive my department as..." $(100=$ entirely transparent, $80=$ largely transparent, $60=$ rather transparent, $40=$ rather intransparent, $20=$ largely intransparent, $0=$ entirely intransparent). Values entered by participants were recoded into values ranging from 1 to 5 (0-20 into 1, 21-40 into 2, 41-60 into 3, 61-80 into 4, 81-100 into 5). Additionally, to assess transparency regarding different facets of departmental structures and processes, four items were generated to be rated on a 5-point Likert scale. Participants were asked to indicate the extent to which they agree with the statement "Specifically, my department is clear and transparent to me regarding..." The four items were "...structural data (e.g., student numbers)," "...distribution of resources (e.g., rooms, jobs/positions)," "...performance data (e.g., faculty-student ratios, evaluation results)," and "...external activities (e.g., industry contacts)." The items were recoded in a way that higher numbers represent the higher agreement (ranging from 1 "fully disagree" to 5 "fully agree").

To examine whether these five items (i.e., the graphical indicator of overall transparency and the four items on transparency regarding specific facets) reflect a unidimensional construct as expected, we performed confirmatory factor analysis. Initially, the results revealed an unsatisfactory model fit. Specifically, the RMSEA of our initial model was 0.14 , clearly above the recommended cutoff criterion of 0.06 (Hu and Bentler 1999). Modification indices suggested correlated errors in connection with one of the four facet-specific transparency items, namely the item on transparency regarding external activities (e.g., industry contacts). Moreover, the proportion of missing values on this item was about twice as high as on the remaining transparency items, which points to the possibility that this item may have been more difficult to understand, or seen as less relevant by the participants, than the other transparency-related items. An additional analysis in which missing values were estimated with the procedure included in AMOS revealed similar fit problems $(R M S E A=0.14)$. We therefore excluded this item from the perceived transparency scale. This led to a unifactorial model with good model fit $\left(\chi^{2}[2]=7.67, p=0.02 ; \chi^{2} / d f=3.83 ; C F I=1.00\right.$; $R M S E A=0.04 ;$ PCLOSE $=0.597 ; S R M R=0.01$; Iacobucci 2010). The reliability of the resulting 4-item measure (Cronbach's $\alpha=0.78$ ) was adequate (Nunnally 1978). 


\subsubsection{Satisfaction with working conditions}

Overall satisfaction with the current working conditions was assessed by a single item. Specifically, we asked the participants to state how they_-generally speaking-assess their satisfaction with the current situation with regard to teaching and research at their university ("With my working situation, I am, all in all...."). The item was rated on a 5-point Likert scale from "very satisfied" to "very dissatisfied" and recoded such that higher values represent higher satisfaction. Although our questionnaire also contained items on satisfaction with specific job facets (e.g., time for research, teaching workload), we used this global measure of job satisfaction, as we expected transparency to affect job satisfaction at a very general level. This is consistent with earlier research, which has shown that single-item measures of (overall) job satisfaction are sensible, robust, and of adequate reliability (Wanous et al. 1997; Scarpello and Campbell 1983).

\subsubsection{Intent to leave}

As the most immediate precursors of actual turnover, research has conceptualized withdrawal cognitions, which encompass thoughts of quitting, intentions to search for employment elsewhere, and the explicit willingness to leave the organization (Tett and Meyer 1993; Mobley et al. 1979). Usually, the decision to leave is influenced by labor market conditions (e.g., the opening of positions) as well as by the perceived chances of getting an alternative offer (Bothma and Roodt 2013; Mobley et al. 1979). Therefore, the professors' intent to leave was assessed by the question of whether or not they would opt for an employer change if given the chance to do so: "Taking into account your current working situation: Would you consider to leave from your university if this was possible?" The professors could choose between the following answers (percentages of "yes" responses to each of the items are shown in parentheses): "No" (43.4\%); "Yes, to another Bavarian university" (28.1\%); "Yes, to another German university" (32.8\%); "Yes, to a university in another country" (26.5\%); "Yes, to a German research institute" (20.9\%); "Yes, to a research institute in another country" (17.6\%); and "Yes, to an organization with no relation to higher education or research" (9.2\%). Multiple responses within the different turnover options were allowed. For the analysis, we aggregated the responses to a single dichotomous item indicating "yes" if any of the different turnover options was answered positively, as we were interested in overall intent to leave. As the last item indicates a turnover option outside the research and higher education system and may thus assess a distinct aspect of intentions to leave, we also formed a separate variable without this final item and performed additional analyses with only the final item as a dependent variable as a robustness check. ${ }^{2}$

\subsubsection{Controls}

To account for contextual effects on the hypothesized relationships, we included a number of control variables. The type of university the participating professors were employed by at the time of the survey was included as a variable with two

\footnotetext{
2 We thank an anonymous reviewer for this suggestion.
} 
categories (0 "research university", 1 "university of applied sciences"). Participants indicated whether they worked full-time or part-time, which was included as a dichotomous variable (0 "full-time", 1 "part-time"). Moreover, their rank according to the classification of the German academic system (W2/W3/C3/C4) was included as a dummy variable with W2 being the reference category. Additionally, we included dummy coded variables indicating the professors' subject area (categories based on the standard German classification of the higher education system), with "economics/law/social sciences" being the reference category. As the endowment of a professors' chair may play a role in turnover decisions, we included a variable indicating the yearly financial endowment of the chair, which was recoded to seven categories (1 “0-5000”/2 “5001-10,000”/3 “10,001-20,000”/4 "20,001-30,000”/5 “30,001-40,000”/6 “40,001-50,000”/7 “> 50,000”).

\section{Results}

Descriptive statistics and correlations of the study variables are shown in Table 1.

Hypotheses were tested using ordinary least square (OLS) regression analyses (for satisfaction as an outcome) and logistic regression analyses (for intent to leave as an outcome). Mediation analysis and exploratory analyses of moderation effects were conducted with the SPSS macro PROCESS (version 3.4; Hayes 2017).

Hypothesis 1 proposed a positive relationship between perceived transparency and satisfaction with the current work situation. To test this hypothesis, we regressed satisfaction with the current work situation on perceived transparency in an OLS regression (Table 2). Perceived transparency showed a significant positive effect on satisfaction with the current work situation over and above all control variables, $B=$ $0.33, p<0.01, \Delta R^{2}=0.11, R^{2}=0.13, F(17,1588)=14.52, p<0.01$, indicating that higher perceived transparency is associated with higher satisfaction with working conditions. We thus conclude that Hypothesis 1 is supported.

Hypothesis 2 predicted a negative relationship between perceived transparency and the intent to leave the current organization. In a logistic regression with perceived transparency (and all our control variables) as predictor and intent to leave as outcome (Table 3), perceived transparency showed a significant negative effect on intent to leave $(\mathrm{B}=-0.57, \mathrm{p}<0.01, \mathrm{OR}=0.57)$, indicating that higher transparency lowers the odds of intending to leave the organization. Specifically, as the odds ratio indicates, for each unit that transparency increases (while keeping all other variables constant), the odds of intending to leave are smaller by a factor of 0.57 . Thus, we conclude Hypothesis 2 to be supported as well. We also performed this analysis with satisfaction with working conditions included as an additional control variable. As this did not alter the direction and significance of the effect of transparency on intent to leave $(B=-0.39$, $\mathrm{p}<0.01, \mathrm{OR}=0.68$ ), we report the results without satisfaction as a control variable in Table 3. Additionally, we ran a separate analysis for intent to leave within and outside the research and higher education system. For turnover options for another higher education or research institution, the significance, direction, and size of the effect remained almost identical $(\mathrm{B}=-0.56, \mathrm{p}<0.001)$, whereas the effect for entirely 


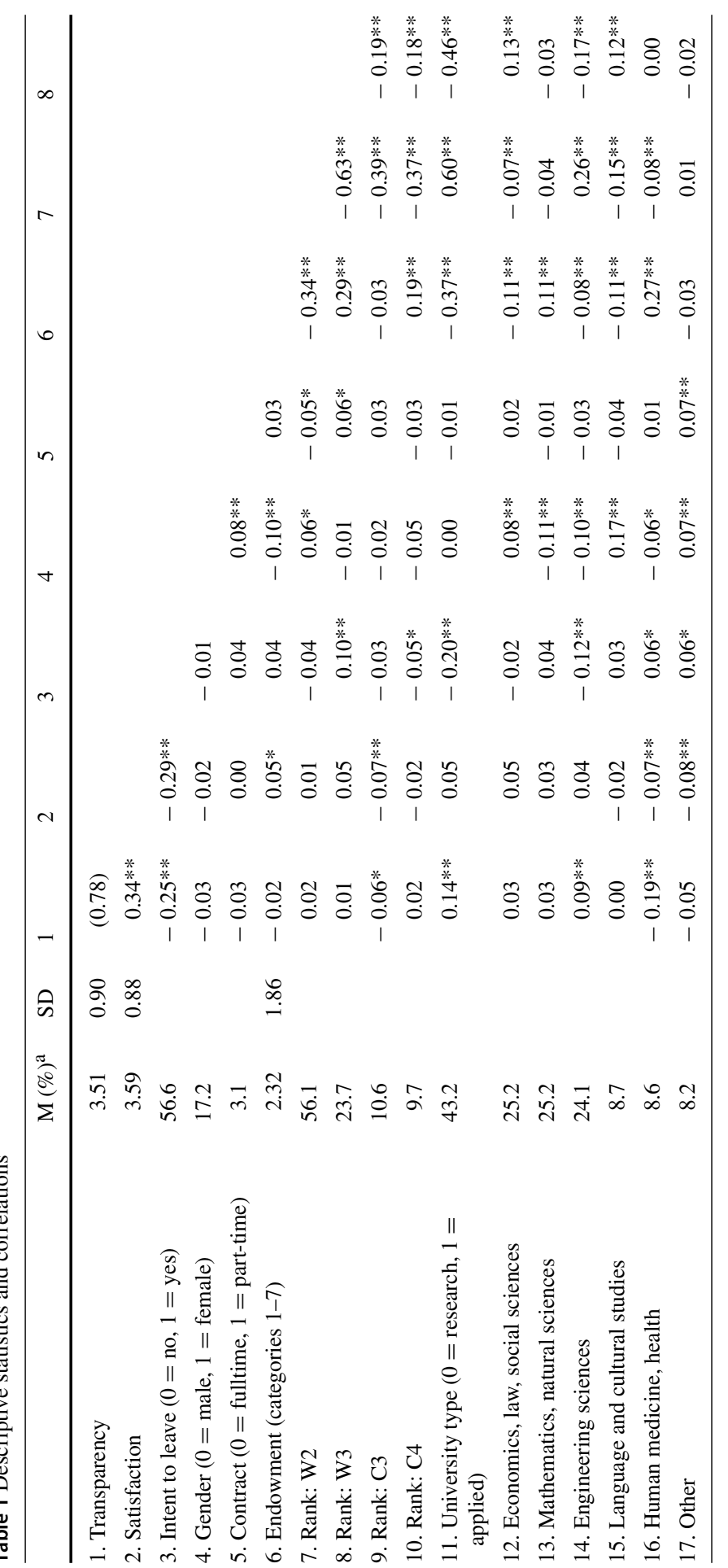




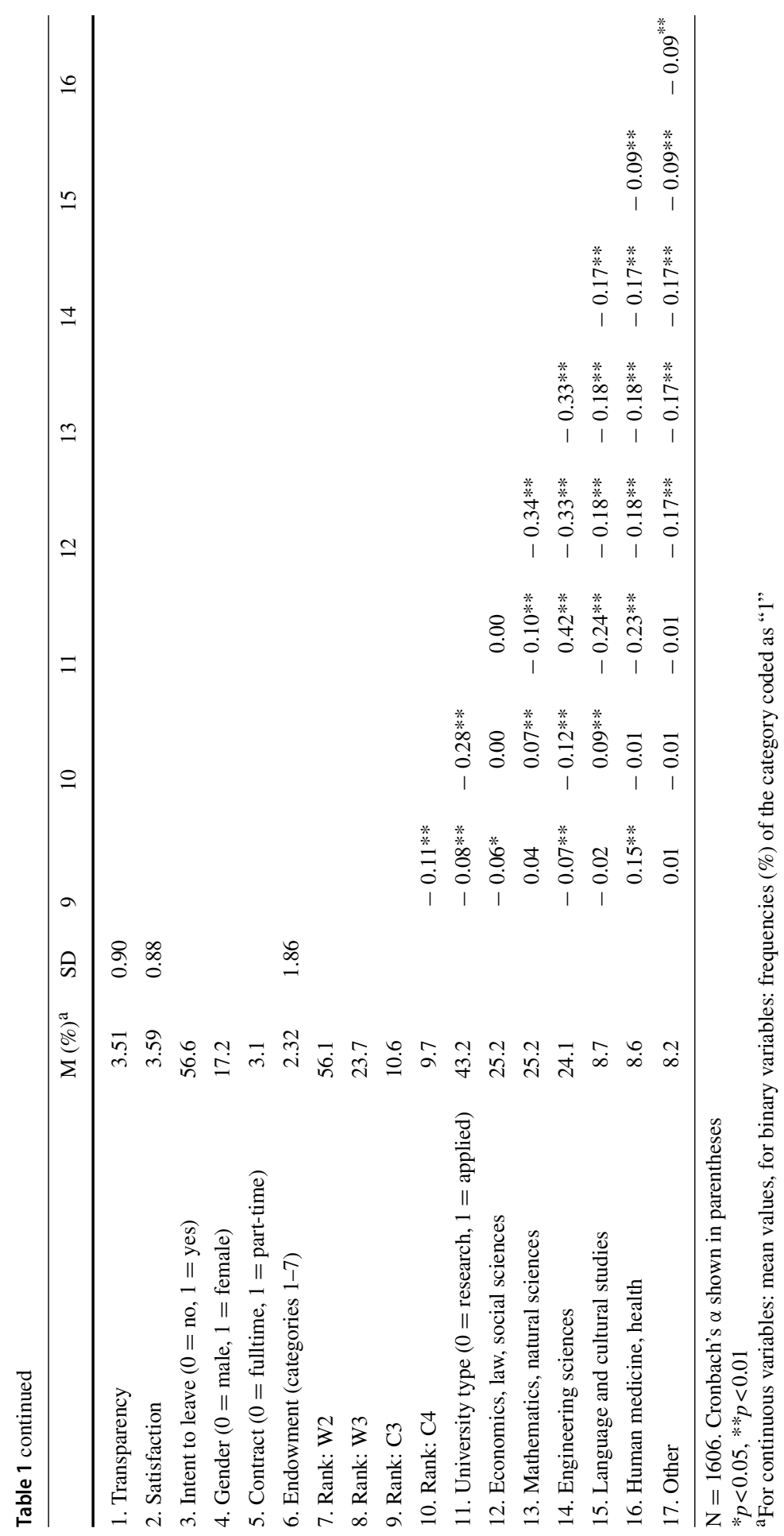


Table 2 Effect of transparency on satisfaction with work situation

\begin{tabular}{|c|c|c|c|c|c|}
\hline & $\mathrm{B}$ & S. E. & Beta & $\mathrm{t}$ & Sig. \\
\hline Constant & 2.44 & 0.10 & & 23.43 & 0.00 \\
\hline Gender $(0=$ male, $1=$ female $)$ & 0.00 & 0.06 & 0.00 & -0.04 & 0.97 \\
\hline Contract $(0=$ full-time, $1=$ part-time $)$ & 0.05 & 0.12 & 0.01 & 0.42 & 0.68 \\
\hline Endowment (EUR) & 0.03 & 0.01 & 0.07 & 2.36 & 0.02 \\
\hline Rank: W3 & 0.02 & 0.07 & 0.01 & 0.37 & 0.71 \\
\hline Rank: C3 & -0.14 & 0.07 & -0.05 & -1.87 & 0.06 \\
\hline Rank: C4 & -0.10 & 0.08 & -0.03 & -1.26 & 0.21 \\
\hline University type $(0=$ research, $1=$ applied sciences $)$ & 0.02 & 0.06 & 0.01 & 0.26 & 0.80 \\
\hline Subject area: mathematics, natural sciences & -0.04 & 0.06 & -0.02 & -0.59 & 0.55 \\
\hline Subject area: engineering sciences & -0.06 & 0.06 & -0.03 & -0.90 & 0.37 \\
\hline Subject area: language, cultural studies & -0.09 & 0.08 & -0.03 & -1.01 & 0.31 \\
\hline Subject area: human medicine, health sciences & -0.11 & 0.09 & -0.03 & -1.21 & 0.23 \\
\hline Subject area: other & -0.25 & 0.08 & -0.08 & -2.93 & 0.00 \\
\hline Transparency & 0.33 & 0.02 & 0.33 & 13.87 & 0.00 \\
\hline
\end{tabular}

Dependent variable: Satisfaction. $N=1606$. Reference category for rank: W2, reference category for subject area: economics/law/social sciences

leaving the research and higher education system was somewhat smaller but still substantial and significant $(\mathrm{B}=-0.41, \mathrm{p}<0.001)$.

Hypothesis 3 predicted an indirect effect of transparency on intent to leave. Supporting this hypothesis, our analysis yielded a significant negative indirect effect of transparency on intent to leave through satisfaction (indirect effect: $a \times b=-0.23$, bootstrapped $\mathrm{CI}$ between -0.29 and $-0.17, \mathrm{p}<0.05)$. In addition to this indirect effect, transparency exhibited a direct impact on intent to leave that was independent of satisfaction $(\mathrm{B}=-0.39$; $\mathrm{CI}[-0.52 ;-0.25])$. Thus, the effect of transparency on intent to leave was partially and not fully mediated through satisfaction. ${ }^{3}$

\section{Discussion}

\subsection{Summary and implications for research and practice}

As universities increasingly provide professors with information on organizational processes and outcomes, our study investigates the relationship between professors' perception of such transparency and their satisfaction and intentions to leave. In line with our hypotheses, our results indicate a positive effect of perceived transparency on satisfaction with current job conditions, and a negative impact of

\footnotetext{
3 We repeated all our hypothesis tests without including the control variables, which led to the same conclusions regarding our hypothesis tests and yielded very similar coefficients (H1: effect of transparency on satisfaction, $\mathrm{B}=0.34, \mathrm{p}<0.001 ; \mathrm{H} 2$ : effect of transparency on intent to leave, $\mathrm{B}=-0.60, \mathrm{p}<0.001)$, $\mathrm{H} 3$ : indirect effect of transparency on intent to leave via satisfaction $(B=-0.22$, bootstrapped $\mathrm{CI}[-0.27$; $-0.16])$.
} 
Table 3 Effect of transparency on intent to leave

\begin{tabular}{lrrrrrr}
\hline & \multicolumn{1}{c}{ B } & S.E. & Wald & df & Sig. & Exp (B) \\
\hline Constant & 2.99 & 0.29 & 105.00 & 1.00 & 0.00 & 19.91 \\
Gender $(0=$ male, $1=$ female) & -0.19 & 0.15 & 1.59 & 1.00 & 0.21 & 0.83 \\
Contract $(0=$ full-time, $1=$ part-time $)$ & 0.45 & 0.33 & 1.84 & 1.00 & 0.17 & 1.57 \\
Endowment (EUR) & -0.02 & 0.03 & 0.21 & 1.00 & 0.64 & 0.98 \\
Rank: W3 & -0.27 & 0.18 & 2.27 & 1.00 & 0.13 & 0.77 \\
Rank: C3 & -0.67 & 0.19 & 11.92 & 1.00 & 0.00 & 0.51 \\
Rank: C4 & -1.04 & 0.22 & 22.84 & 1.00 & 0.00 & 0.36 \\
University type (0 = research, 1 = applied sciences) & -1.03 & 0.16 & 39.52 & 1.00 & 0.00 & 0.36 \\
Subject area: mathematics, natural sciences & 0.16 & 0.16 & 1.09 & 1.00 & 0.30 & 1.18 \\
Subject area: engineering sciences & -0.12 & 0.16 & 0.57 & 1.00 & 0.45 & 0.89 \\
Subject area: language, cultural studies & 0.04 & 0.22 & 0.03 & 1.00 & 0.87 & 1.04 \\
Subject area: human medicine, health sciences & -0.16 & 0.24 & 0.44 & 1.00 & 0.51 & 0.85 \\
Subject area: other & 0.35 & 0.22 & 2.49 & 1.00 & 0.11 & 1.42 \\
Transparency & -0.56 & 0.06 & 77.10 & 1.00 & 0.00 & 0.57 \\
\hline Depen
\end{tabular}

Dependent variable: Intent to leave $(0=$ no, $1=$ yes $) . N=1606$. Reference category for rank: W2, reference category for subject area: economics/law/social sciences

perceived transparency on intent to leave. Our findings suggest that information disclosure-specifically, the department's openness about structures, processes, and resources - is not only a relevant factor for how satisfied professors are with their working conditions but may also result in a reduction of professors' intentions to leave.

With our specific results about academia, we add to the existing literature about reasons for turnover. For example, Williams and Hollenbeck (2006) reported a negative relationship between job satisfaction and turnover and intent to leave (Smart 1990; Shore and Martin 1989) but not within the academic context. This report is in line with research from Rosser (2004), Griffeth et al. (2000), and Cotton and Tuttle (1986). Thus, our results lend support to the view that professors who are feeling well-informed and perceiving their university administration and department as transparent are more satisfied and express less often the wish to leave their university. In particular, our measure captured the extent to which professors perceive that they get or have access to clear and comprehensible information about resources, as well as structural and performance data about their department and faculty. Thus, our findings indicate that these particular factors are related to higher satisfaction and lower intention to leave among professors.

To further substantiate our results and explore potential institutional differences, we performed exploratory moderation analyses to examine whether the effects of transparency are different for the two types of universities included in our sample (i.e., research universities and universities of applied sciences). Our results indicate that the strength of the effect of transparency on satisfaction does not significantly differ between the two university types. However, we found a significant interaction effect 
between university type and transparency on intent to leave $(B=-0.29, p<0.05)$. While the effect of transparency on intent to leave was present in both subgroups, it was stronger for universities of applied sciences $(B=-0.73, p<0.01,95 \%$ CI [$0.92,-0.54], \mathrm{OR}=0.48)$ than for research universities $(B=-0.43, p<0.01,95 \%$ CI $[-0.60,-0.27], \mathrm{OR}=0.65)$. Thus, the effect of transparency on satisfaction and on intent to leave appears to be robust across the two types of institutions. However, transparency seems to be more important for intent to leave in universities of applied sciences than in research universities. A possible explanation for this finding is that, in research universities, turnover may be driven more strongly by factors related to the desire to pursue individual and institutional reputation in research than by factors related to the internal organizational climate. This is because, in research universities, professors are selected for their competitiveness in the area of research, which is likely to remain a strong driver of career-related decisions. Moreover, using turnover or displaying turnover intentions to (re-)negotiate compensation and benefits (e.g., sabbaticals) may be more common in research universities than in universities of applied sciences, as such negotiations are frequently based on research output as a measure of performance. In line with this potential explanation, the overall mean level of intent to leave was significantly higher for research universities $(M=0.65, S D=$ 0.48 ) than for universities of applied sciences $(M=0.44, S D=0.50, p<0.01)$, so the base rate of intentions to leave in universities of applied sciences seems to be lower than that of research universities but appears to be more sensitive to the effects of transparency.

Interestingly, while our results revealed an indirect effect of transparency on intent to leave via job satisfaction as hypothesized, there was an additional direct effect of transparency on intent to leave that was not mediated by job satisfaction. That is plausible, given that turnover research suggests that satisfaction is not the only driver of turnover and that other factors play a role as well (for review, see Hom et al. 1992, 2017). For example, organizational commitment is known to be negatively associated with turnover (Griffeth et al. 2000) and might be positively affected by transparency, as individuals who have access to internal data may feel more involved in key structures and processes and thus feel more committed to their university.

Overall, our results lend empirical support to Lynch's (2014) conclusion about the importance of transparent governance in higher education, especially in times of novel strategic challenges and organizational change. Our findings emphasize the importance of an adequate information policy and information management. Based on the results of our study, university administration and departments should aim at clear and transparent communication regarding the structure, resources, and performance of their units. While our research was based on overall assessments of transparency, the availability of and need for specific information may differ between universities. The university administration could therefore assess satisfaction with particular aspects of information transparency at a more detailed level to understand more specifically where a lack of transparency is perceived and which information needs to be provided to whom to close any perceived gaps. By following this strategy, universities make sure that they provide the right kind of information that will be perceived as useful and increase subjective perceptions of transparency. 
This seems particularly important today, as universities are confronted with the necessity to undergo a digital transformation, following fast-paced developments in information technology and global market demands (Backes-Gellner et al. 2019; McCluskey and Winter 2012). In such dynamic environments, it may be more important than ever to provide transparency to involve organizational members more closely in strategic decisions and changes (Strobel et al. 2017). However, the ongoing organizational change of HEI is a complex process (Küpper et al. 1998), especially since universities nowadays are faced with a global, knowledge-based society and highly mobile employees and students. Furthermore, a variety of models of future higher education is emerging, such as profit-oriented adult-centered universities, distance education universities, corporate universities, university-industry strategic alliances, and global multinational universities. This implies a rather complex change or transformation process. In light of such far-reaching strategic challenges, distributing information about the ongoing changes seem particularly crucial. Otherwise, universities may run the risk of losing the competition for high-potential academics.

\subsection{Limitations and directions for future research}

This study sheds light on transparency in HEIs - a topic where theorizing and empirical data have been largely lacking so far. Like many other studies exploring novel research fields, our study also has limitations.

First of all, our data is based on self-report measures. Thus, the interrelationships between our measures may be affected by common-method variance. Further studies could address this by including more objective measures of transparency (e.g., document analyses regarding transparency policies) or survey measures from other sources (e.g., administrative staff). Also, our study does not include objective data on turnover, which would be good to include in future studies: although turnover intention is frequently used as a proxy of actual turnover (cf. Hom et al. 2017), actual turnover may be influenced by additional variables (e.g., employment opportunities, cf. Carsten and Spector 1987). Another limitation regarding our measurement is that we assessed general job satisfaction with a single item. This is considered acceptable but not ideal in the literature (cf. Wanous et al. 1997). To cover the construct of overall job satisfaction more broadly and enhance measurement reliability, future studies should use a validated multi-item measure of job satisfaction.

Second, as we granted anonymity to our participants and did not record university names to prevent identification, we cannot statistically account for the dependencies resulting from our nested data structure (i.e., professors' responses nested within universities). We therefore encourage further research to account for such effects and to use the opportunity to connect university-level data with subjective responses of university members in a multilevel design. That may provide the opportunity to differentiate effects resulting from objective transparency at university level (i.e., factual availability of information and data) from the subjective experience of transparency at the individual level.

Third, our measure assesses transparency from the perspective of receiving information: our participants were asked if information is transparent and available to them 
and not about themselves. Bernstein (2017, p. 238) pointed out that an "accurate awareness of others" resulting from transparency may have positive effects on outcomes, while the "awareness of others watching" may have negative effects, as it can trigger secretive behaviors aimed at maintaining privacy. As our study did not assess this "flip side of the coin," we encourage further research to investigate such undesired side effects of transparency and the conditions under which they are likely to occur.

Fourth, although we have a large sample of participants, it includes full professors at Bavarian universities only and not at other universities in Germany or other countries. And though their working condition is usually also characterized by a high level of autonomy and power (e.g., Ren and Li 2013; Etzkowitz et al. 2000; Altbach 1996), the professors' employment situation in other countries usually differs from the governance and tenure system at German universities. Therefore, additional studies within and across different contexts would be desirable to examine the generalizability of our findings more extensively.

On a more general level, we encourage future studies to investigate more deeply the mechanisms and boundary conditions of the effects of transparency on faculty attitudes and behaviors. Given that the effect of transparency on intentions to leave was not fully mediated by job satisfaction, additional psychological mediators that translate transparency perceptions into turnover intentions should be investigated. Moreover, future studies should investigate the moderating variables that function as boundary conditions or catalysts of the relationship between perceived transparency and turnover intentions. For example, building and testing theory on potential institutional differences that have been indicated by our exploratory analyses would be desirable. Another possible factor that could influence the strength (and maybe even the direction) of the effect of transparency is the extent to which the information that is available to organizational members is relevant for individual performance evaluations and incentives.

Moreover, further studies could take advantage of the ongoing digital transformation in universities as a research context for investigating whether increased transparency improves attitudes towards and adoption of such changes. An interesting opportunity would be to include changes in university policies regarding transparency in the study design. A particularly valuable research strategy in such a setting would be conducting field experiments to establish effects of transparency, which the present study did not address. Ideally, these would be combined with longitudinal studies that aim at a better understanding of how the effect of transparency unfolds over time, given the relatively long-term nature of the academic job market.

\section{Conclusion}

Our research set out to understand how faculty members perceive transparency in higher education institutions and how this affects their satisfaction and intent to leave their university. Our results indicate that it is important for HEIs to disclose information and provide transparency regarding their structures, distribution of resources, and performance to maintain satisfaction among professors and retain talented faculty. We encourage future research to further examine how and under which conditions 
transparency in research and HEIs affects outcomes that are relevant for these organizations' competitiveness, performance, and success in a growing international higher education market.

Acknowledgements Open Access funding provided by Projekt DEAL.

Funding This study was funded by Bayerisches Staatsinstitut für Hochschulforschung und Hochschulplanung.

Open Access This article is licensed under a Creative Commons Attribution 4.0 International License, which permits use, sharing, adaptation, distribution and reproduction in any medium or format, as long as you give appropriate credit to the original author(s) and the source, provide a link to the Creative Commons licence, and indicate if changes were made. The images or other third party material in this article are included in the article's Creative Commons licence, unless indicated otherwise in a credit line to the material. If material is not included in the article's Creative Commons licence and your intended use is not permitted by statutory regulation or exceeds the permitted use, you will need to obtain permission directly from the copyright holder. To view a copy of this licence, visit http://creativecommons.org/licenses/by/4.0/.

\section{References}

Altbach PG (ed) (1996) The international academic profession: portraits of fourteen countries. Carnegie Foundation for the Advancement of Teaching, Princeton, NJ

Backes-Gellner U, Böhringer C, Cantner U, Harhoff D, Hölzle K, Schnitzer M (2019) Gutachten zu Forschung, Innovation und technologischer Leistungsfähigkeit Deutschlands 2019. EFI, Berlin

Bernstein ES (2012) The transparency paradox: a role for privacy in organizational learning and operational control. Admin Sci Q 57(2):181-216

Bernstein ES (2017) Making transparency transparent: the evolution of observation in management theory. Acad Manag Ann 11(1):217-266

Beshears J, Choi JJ, Laibson D, Madrian BC, Milkman KL (2015) The effect of providing peer information on retirement savings decisions. J Finance 70(3):1161-1201

Bleiklie I, Kogan M (2007) Organization and governance of universities. High Educ Policy 20:477-493

Bothma CF, Roodt G (2013) The validation of the turnover intention scale. SA J Hum Resour Manag 11(1):1-12

Bozeman B, Gaughan M (2011) Job satisfaction among university faculty: individual, work, and institutional determinants. J High Educ 80(6):154-186

Buell RW, Kim T, Tsay CJ (2016) Creating reciprocal value through operational transparency. Manag Sci 63(6):1673-1695

Carsten JM, Spector PE (1987) Unemployment, job satisfaction, and employee turnover: a meta-analytic test of the Muchinsky model. J Appl Psychol 72(3):374-381

Chen AK (2006) Bureaucracy and distrust: Germaneness and the paradoxes of academic freedom doctrine. Univ Colo Law Rev 77:955-986

Colquitt JA (2001) On the dimensionality of organizational justice: a construct validation of a measure. J Appl Psychol 86(3):386-400

Cotton JL, Tuttle JM (1986) Employee turnover: a meta-analysis and review with implications for research. Acad Manag Rev 11(1):55-70

Cullen J, Joyce J, Hassall T, Broadbent M (2003) Quality in higher education: from monitoring to management. Qual Assur Educ 11(1):5-14

Cummings JN (2004) Work groups, structural diversity, and knowledge sharing in a global organization. Manag Sci 50(3):352-364

Daft RL, Lengel RH (1986) Organizational information requirements, media richness and structural design. Manag Sci 32(5):554-571

Destatis (2020) Hochschulen. https://www.destatis.de/DE/Themen/Gesellschaft-Umwelt/BildungForschung-Kultur/Hochschulen/_inhalt.html, abgerufen am 26.03.2020 
Eisenberg EM, Monge PR, Miller KI (1984) Involvement in communication networks as a predictor of organizational commitment. Hum Commun Res 10:179-201

Etzkowitz H, Webster A, Gebhardt C, Terra BRC (2000) The future of the university and the university of the future: evolution of ivory tower to entrepreneurial paradigm. Research Policy 29(2):313-330

Griffeth RW, Hom PW, Gaertner S (2000) A meta-analysis of antecedents and correlates of employee turnover: update, moderator tests, and research implications for the next millennium. J Manag 26(3):463-488

Hayes AF (2017) Introduction to mediation, moderation, and conditional process analysis: a regressionbased approach. Guilford Press, New York

Henderson JC, Venkatraman N (1993) Strategic alignment: leveraging information technology for transforming organizations. IBM Syst J 32(1):4-16

Hom PW, Caranikas-Walker F, Prussia GE, Griffeth RW (1992) A meta-analytical structural equations analysis of a model of employee turnover. J Appl Psychol 77(6):890-909

Hom PW, Lee TW, Shaw JD, Hausknecht JP (2017) One hundred years of employee turnover theory and research. J Appl Psychol 102(3):530-545

Hu LT, Bentler PM (1999) Cutoff criteria for fit indexes in covariance structure analysis: conventional criteria versus new alternatives. Struct Equ Model 6(1):1-55

Iacobucci D (2010) Structural equations modeling: fit indices, sample size, and advanced topics. J Consum Psychol 20(1):90-98

Jansen D (ed) (2007) New forms of governance in research organizations: disciplinary approaches, interfaces and integration. Springer Science and Business Media, New York

Judge TA, Weiss HM, Kammeyer-Mueller JD, Hulin CL (2017) Job attitudes, job satisfaction, and job affect: a century of continuity and of change. J Appl Psychol 102(3):356-374

Kiefer T (2005) Feeling bad: antecedents and consequences of negative emotions in ongoing change. J Organ Behav 26(8):875-897

Krayer KJ, Westbrook L (1986) The relationship between communication load and job satisfaction. World Commun 15:85-99

Küpper HU (2000) Denkmuster verändern. Wettbewerbsorientierte Strukturierung des Führungssystems von Universitäten. Forschung Lehre 3:116-118

Küpper HU (2003) Die Hochschulen sind mehr in Bewegung, als man von außen wahrnimmt. Beiträge zur Hochschulforschung 3:122-126

Küpper HU (2007) Neue Entwicklungen im Hochschulcontrolling. Zeitschrift für Controlling und Management, Sonderheft 3:82-90

Küpper HU (2009a) Effizienzreform der deutschen Hochschulen nach 1990-Hintergründe, Ziele, Komponenten. Beiträge zur Hochschulforschung 4:50-75

Küpper HU (2009b) Evaluation von Forschung und Lehre. In: Geis M-E (ed) Hochschulrecht im Freistaat Bayern. Handbuch für Wissenschaft und Praxis, Heidelberg, pp 201-215

Küpper HU, Sinz [Hrsg.] E (1998) Gestaltungskonzepte für Hochschulen. Effizienz, Effektivität, Evolution. Schäffer, Stuttgart

Lawrence JH, Celis S, Kim HS, Lipson SK, Tong X (2014) To stay or not to stay: retention of Asian international faculty in STEM fields. High Educ 67(5):511-531

Lee Y, Lee J, Hwang Y (2015) Relating motivation to information and communication technology acceptance: self-determination theory perspective. Comput Hum Behav 51:418-428

Lynch M (2014) Diverse conversations: the importance of transparency in governance. Diverse issues in Higher Education. http://diverseeducation.com/article/65913/. Accessed 25 May 2018

March JG, Simon HA (1958) Organizations. Wiley, New York

Martin TN Jr (1979) A contextual model of employee turnover intentions. Acad Manag J 22(2):313-324

Martocchio J, Jimeno DI (2003) Employee absenteeism as an affective event. Hum Resour Manag Rev 13(2):227-241

Mayr K, Peri G (2009) Brain drain and brain return: theory and application to Eastern-Western Europe. BE J Econ Anal Policy 9(1):49

McCluskey FB, Winter ML (2012) The idea of the digital university: ancient traditions, disruptive technologies and the battle for the soul of higher education. Westphalia Press, Washington, DC

McCluskey FB, Winter ML (2014) Academic freedom in the digital age. On the Horizon 22(2). https:// www.researchgate.net/publication/262574744_Academic_freedom_in_the_digital_age. Accessed 25 Jan 2019 
Miner AG, Glomb TM, Hulin C (2005) Experience sampling mood and its correlates at work. J Occup Organ Psychol 78(2):171-193

Mobley WH, Griffeth RW, Hand HH, Meglino BM (1979) Review and conceptual analysis of the employee turnover process. Psychol Bull 86(3):493

Morton MS (1991) The corporation of the 1990s: information technology and organizational transformation. Oxford University Press, Oxford

Mullins LJ (1993) Management and organizational behavior. 3rd edn. Pitman Publishing 19. Rld Commun 15:85-93

Musselin C (2004) Are Universities specific organisations? In: Krücken GA, Kosmützky A, Torka M (eds) Towards a multiversity? Universities between global trends and national traditions. Transcriptverlag, Bielefeld, pp 63-84

NPEC National Postsecondary Education Cooperative (2009) Information required to be disclosed under the Higher Education Act of 1965: suggestions for dissemination (updated) (NPEC 2010-831v2), prepared by Carol Fuller and Carlo Salerno. Coffey Consulting, Washington DC

Nunnally JC (1978) Psychometric theory. McGraw-Hill, New York

O'Meara K, Bennett JC, Neihaus E (2016) Left unsaid: the role of work expectations and psychological contracts in faculty careers and departure. Rev High Educ 39(2):269-297

O'Reilly CA (1983) The use of information in organizational decision making: a model and some propositions. Res Organ Behav 5:103-139

O'Reilly CA, Chatman JA, Anderson JC (1987) Message flow and decision making. In: Jablin FM, Putman LL, Roberts KH, Porter LW (eds) Handbook of organizational communication: an interdisciplinary perspective. Sage, Newbury Park, pp 600-623

Paradeise C, Reale E, Bleiklie I, Ferlie E (eds) (2009) University governance. Springer, Amsterdam

Ramírez Y, Tejada A, Baidez A (2015) Intellectual capital and transparency in universities: an empirical study. Int Sch Sci Res Innov 9(2):9

Randhahn S (2017) Information management in higher education institutions. Tredition, Hamburg

Remhof S (2008) Auswanderung von Akademikern aus Deutschland. Gründe, Auswirkungen und Gegenmaßnahmen. Tectum Verlag, Marburg

Ren K, Li J (2013) Academic freedom and university autonomy: a higher education policy perspective. High Educ Policy 26(4):507-522

Rosenfeld LB, Richman JM, May SK (2004) Information adequacy, job satisfaction and organizational culture in a dispersed-network organization. J Appl Commun Res 32(1):28-54

Rosser V (2004) Faculty members' intentions to leave: a national study on their worklife and satisfaction. Res High Educ 45(3):285-309

Russell C (1993) Academic freedom. Routledge, London

Sanchez MP, Elena S (2005) Intellectual capital in universities. Improving transparency and internal management. J Intellect Cap 7(4):529-548

Sandberger G (2019) Hochschulgovernance statt Unternehmerische Hochschule? Zu den Empfehlungen des Wissenschaftsrats. Ordnung in der Wissenschaft 3:137-150

Scarpello V, Campbell JP (1983) Job satisfaction: are all the parts there? Pers Psychol 36(3):577-600

Schimank U, Lange S (2009) Germany: a latecomer to new public management. In: Paradeise C, Reale E, Bleilklie I, Ferlie E (eds) University governance: Western European comparative perspectives. Springer, Dordrecht

Shore LM, Martin HJ (1989) Job satisfaction and organizational commitment in relation to work performance and turnover intentions. Hum Relat 42(7):625-638

Smart JC (1990) A causal model of faculty turnover intentions. Res High Educ 31(5):405-424

StatB (2014) Personalbestand an den Hochschulen in Bayern 2014. Statistische Berichte-B34103 201400. Bayerisches Landesamt für Statistik, München

Stohl C, Stohl M, Leonardi PM (2016) Managing opacity: information visibility and the paradox of transparency in the digital age. Int J Commun 10:123-137

Strobel M, Welpe I (2017) Hochschule 4.0. Die Zukunft der Hochschule erfinden. Forsch Lehre 23(4):316-318

Strobel M, Tumasjan A, Spoerrle M, Welpe IM (2017) Fostering employees' proactive strategic engagement: individual and contextual antecedents. Hum Res Manag J 27(1):113-132

Tanczer LM, McConville R, Maynard P (2016) Censorship and surveillance in the digital age: the technological challenges for academics. Forum on censorship in security studies, pp 346-355 
Tapscott D, Ticoll D (2012) The naked corporation: how the age of transparency will revolutionize business, 6th edn. Simon and Schuster, Free Press, New York

Tett RP, Meyer JP (1993) Job satisfaction, organizational commitment, turnover intention, and turnover: path analyses based on meta-analytic findings. Pers Psychol 46:259-293

Thorens J (2006) Liberties, freedom and autonomy: a few reflections on Academia's estate. High Educ Policy 19(1):87-110

Tritah A (2008) The brain drain between knowledge-based economies: the European human capital outflows to the U.S. Int Econ 115:65-118

Tumasjan A, Welpe I (2017) Alles Selbstläufer? Ein Überblick zu Motivations- und Anreizsystemen der „Digital Stars“. Organ Entwickl 4:19-22

Wanous JP, Reichers AE, Hudy MJ (1997) Overall job satisfaction: how good are single-item measures? J Appl Psychol 82(2):247-252

Welpe IM, Wollersheim J, Ringelhan S, Osterloh M (2014) Incentives and performance: governance of knowledge-intensive organizations. Springer, Cham

Wendler WS, Stumpf-Wollersheim J, Welpe IM (2017) Business models in the education technology industry: what makes them successful? In: International conference on information systems 2017 proceedings

Wigand RT, Picot A, Reichwald R (1997) Information, organization, and management: expanding markets and corporate boundaries. Wiley, Chichester

Williams CR, Hollenbeck JR (2006) Turnover functionality versus turnover frequency: a note on work attitudes and organizational effectiveness. J Appl Psychol 71(4):606-611

Wilsdon JR, Allen L, Belfiore E et al (2015) The Metric tide: report of the independent review of the role of metrics in research assessment and management. https://doi.org/10.13140/RG.2.1.4929.1363

Zimmer CJ et al (2010) Investigating online information disclosure: effects of information relevance, trust and risk. Inf Manag 47(2):115-123

Publisher's Note Springer Nature remains neutral with regard to jurisdictional claims in published maps and institutional affiliations.

\section{Affiliations}

\section{Yvette E. Hofmann ${ }^{1,2}$ - Maria Strobel $1,3,4$}

$\bowtie \quad$ Yvette E. Hofmann

hofmann@ihf.bayern.de

$凶 \quad$ Maria Strobel

maria.strobel@hs-mainz.de

1 Bayerisches Staatsinstitut für Hochschulforschung und Hochschulplanung (IHF), Lazarettstraße 67, 80636 Munich, Germany

2 Ludwig-Maximilians-Universität München, Munich School of Management, Geschwister-Scholl-Platz 1, 80539 Munich, Germany

3 Technische Universität München, TUM School of Management, Arcisstr. 21, 80333 Munich, Germany

4 Hochschule Mainz, Lucy-Hillebrand-Straße 2, 55128 Mainz, Germany 